\title{
Ultra-stiff metallic glasses through bond energy density design
}

This content has been downloaded from IOPscience. Please scroll down to see the full text.

Download details:

IP Address: 131.111.5.144

This content was downloaded on 15/05/2017 at 09:13

Manuscript version: Accepted Manuscript

Schnabel et al

To cite this article before publication: Schnabel et al, 2017, J. Phys.: Condens. Matter, at press: https://doi.org/10.1088/1361-648X/aa72cb

This Accepted Manuscript is: @ 2017 IOP Publishing Ltd

During the embargo period (the 12 month period from the publication of the Version of Record of this article), the Accepted Manuscript is fully protected by copyright and cannot be reused or reposted elsewhere.

As the Version of Record of this article is going to be / has been published on a subscription basis, this Accepted Manuscript is available for reuse under a CC BY-NC-ND 3.0 licence after a 12 month embargo period.

After the embargo period, everyone is permitted to use all or part of the original content in this article for non-commercial purposes, provided that they adhere to all the terms of the licence https://creativecommons.org/licences/by-nc-nd/3.0

Although reasonable endeavours have been taken to obtain all necessary permissions from third parties to include their copyrighted content within this article, their full citation and copyright line may not be present in this Accepted Manuscript version. Before using any content from this article, please refer to the Version of Record on IOPscience once published for full citation and copyright details, as permissions will likely be required. All third party content is fully copyright protected, unless specifically stated otherwise in the figure caption in the Version of Record.

When available, you can view the Version of Record for this article at: http://iopscience.iop.org/article/10.1088/1361-648X/aa72cb 


\section{Ultra-stiff metallic glasses through bond energy density design}

2 Volker Schnabel ${ }^{1,2 \star}$, Mathias Köhler ${ }^{3}$, Denis Music ${ }^{1}$, Jozef Bednarcik ${ }^{4}$, William J. Clegg ${ }^{5}$, Dierk Raabe ${ }^{3}$, 3 Jochen M. Schneider ${ }^{1}$

$4{ }^{1}$ Materials Chemistry, RWTH Aachen University, Kopernikusstr. 10, D-52074 Aachen, Germany

$5 \quad{ }^{2}$ Laboratory for Nanometallurgy, ETH Zürich, Vladimir-Prelog-Weg 5, CH-8093, Switzerland

${ }^{3}$ Max-Planck-Institut für Eisenforschung, Max-Planck-Straße 1, D-40237 Düsseldorf, Germany

${ }^{4}$ Deutsches Elektronen Synchrotron DESY,FS-PE group, Notkestrasse 85, D-22607 Hamburg, Germany

\section{Abstract}

The elastic properties of crystalline metals scale with their valence electron density. is $17 \%$ greater than the stiffest Co-B based metallic glasses reported in literature.

${ }^{5}$ Department of Materials Science and Metallurgy, 27 Charles Babbage Rd, Cambridge University, U.K.

\section{Similar observations have been made for metallic glasses. However, for metallic} glasses where covalent bonding predominates, such as metalloid metallic glasses, this relationship appears to break down. At present, the reasons for this are not understood. Using high energy X-ray diffraction analysis of melt spun and thin film metallic glasses combined with density functional theory based molecular dynamics simulations, we show that the physical origin of the ultrahigh stiffness in both, metalloid and non-metalloid metallic glasses is best understood in terms of the bond energy density. Using the bond energy density as novel materials design criterion for ultra-stiff metallic glasses, we are able to predict a $\mathrm{Co}_{33.0} \mathrm{Ta}_{3.5} \mathrm{~B}_{63.5}$ short range ordered material by density functional theory based molecular dynamics simulations with a high bond energy density of $0.94 \mathrm{eV} / \AA^{3}$ and a bulk modulus of $263 \mathrm{GPa}$, which 


\section{1. Introduction}

2 The bulk modulus of known materials spans 5 orders of magnitude from $0.001 \mathrm{GPa}$

3 for low-mass-density foams to $440 \mathrm{GPa}$ for diamond [1]. Even for metallic glasses the

4 bulk modulus ranges from $15 \mathrm{GPa}$ for Sr-based glasses [2] to $224 \mathrm{GPa}$ for Co-B

5 based [3-7] metallic glasses. The bulk modulus is a measure for a solid's resistance

6 to volume changes. It is an important property of any structural material. The elastic

7 properties of solids depend on their bond stiffness and the bond density per volume

8 [1]. However, in metallic glasses, where there is a vast range of potential alloy

9 compositions, it is essential for any meaningful alloy design that there are criteria to enable the reliable prediction of high stiffness glasses.

The valence electron density has been proposed as the principal factor determining the bulk stiffness of metals [8], metallic dominated intermetallic compounds $[9,10]$ and polar covalent crystals [11]. Furthermore, cohesive energy density has been observed to correlate with the bulk modulus of metals [12]. Pang et al. [13] extended the well know elastic property - valence electron density design guideline from metals [8] to metallic glasses. The alloying guideline for non-metalloid metallic glasses proposed by Pang et al. [13] relies on the assumption that the elastic properties of metallic glasses can be described by a rule of mixture approach [13] as described by

$$
d=\frac{\sum_{i} x_{i} e_{i}}{\sum_{i} x_{i} \Omega_{i}}
$$

where $d$ denotes the valence electron density, $x_{i}, e_{i}$ and $\Omega_{i}$ the atomic concentration, number of valence electrons $[14,15]$ and atomic volume of the element $i$, respectively [13].

Models for stiffness that are based on molar volume and on the combination of bond coordination number, electronegativity and molar density have been proposed as composition guidelines for metallic [16] and oxide glasses [17], respectively. 
1 Furthermore, atomic packing density has been shown to correlate with Poisson's

2 ratio for oxide glasses, such as aluminates, aluminum silicates and oxynitrides [18].

3 However, this correlation is not observed for chalco-halogenides, because van der

4 Waals interactions are not considered [18]. Furthermore, a reverse trend between the

5 Poisson's ratio and the atomic packing density is observed for the case of borates

6 compared to aluminates, aluminum silicates and oxynitrides [18]. Pang et al.

7 observed that valence electron density as an alloying guideline is limited to metallic

8 glasses where the bonding is not predominantly covalent [13]. Because the origin of

9 the high stiffness in metalloid glasses is not understood, there is no suitable criterion for designing high stiffness glasses. In particular, there is no understanding of the relationship of elastic properties, molar density and how this might be related to the electronic structure.

Here, we introduce the concept of the bond energy density as a criterion for predicting the stiffness, which goes beyond the rule of mixtures in electron density, whilst reflecting the physical origin of the ultrahigh stiffness in both metalloid and nonmetalloid metallic glasses. Furthermore, we demonstrate that it can be used to predict ultra-stiff short range ordered materials of $\mathrm{Co}_{33.0} \mathrm{Ta}_{3.5} \mathrm{~B}_{63.5}$ with a bulk modulus of 263 GPa by density functional theory (DFT) calculations.

\section{Methods}

\subsection{Density functional theory based molecular dynamics simulations}

For the amorphous structure simulations the liquid-quench method [7, 19] was applied. Density functional theory based molecular dynamics simulations were performed with the OpenMX [20] code, version 3.7 based on density functional theory [21]. Electronic potentials with basis functions in the form of linear combination of localized pseudoatomic orbitals and generalized gradient approximation were 
1 employed [22, 23]. An N-point grid larger than $72 \times 72 \times 72$ and a cutoff energy of

2150 Ry was used. As an initial configuration for the simulations a bcc supercell

3 containing 115 atoms was heated to $4000 \mathrm{~K}$ by scaling the velocity, constituting a

4 canonical ensemble. After quenching to $0 \mathrm{~K}$ the structures were relaxed in terms of

5 atomic positions and volume. The sequence of heating to $4000 \mathrm{~K}$, quenching to $0 \mathrm{~K}$

6 and equilibration at the ground state was repeated until the volume difference of $2 \%$

7 was reached between consecutive steps. The ground state calculations were

8 performed using the Vienna $A b$ initio Simulation Package [24], version 5.2.12.

9 Previous reports by Hostert et al. [7] and Schnabel et al. [39] have shown good agreement between ab initio simulation and experiment regarding elastic properties and density for various metallic glasses using 115 atom/simulation cells. Elastic properties were calculated at the ground state after the last heating cycle. The bulk modulus was calculated according to the Birch-Murnaghan equation of state [25], whereas the shear modulus was calculated according to Hill [26]. The Young's modulus was obtained from the shear and bulk moduli [26]. The pair distribution functions $g(r)$ were calculated according to Eq. (2) from the relaxed atomic positions,

$$
g(r)=\frac{1}{4 \pi \rho_{0} r^{2}} \sum_{i} \sum_{j} \frac{b_{i} b_{j}}{\langle b\rangle^{2}} \delta\left(r-r_{i j}\right)
$$

where the sum goes over all pairs of atoms $i$ and $j$ within the system separated by $r_{i j}$ [7]. $b_{i, j}$ denotes the scattering power of atom $i$ and $j$, respectively, and $\langle b\rangle$ is the average scattering power of the system. The average atomic number density and atomic distance is denoted by $\rho_{0}$ and $r$, respectively. To compare to experimental data the pair distribution functions are transformed to reduced pair distribution functions $G(r)$.

$$
\mathrm{G}(r)=4 \pi \rho_{0} r[\mathrm{~g}(r)-1]
$$


1 For the reduced pair distribution function the slope below the lowest bond distance is

2 proportional to the atomic number density. The crystal orbital Hamilton population 3 (COHP) was calculated using the LOBSTER package [27-29]. Here the partial crystal

4 orbital Hamilton population ( $\mathrm{pCOHP}$ ) was integrated to the Fermi level $\varepsilon_{f}$. The bond 5 energy density $\Omega$ was obtained through summation of the integrated pCOHP for all 6 bonds within the first coordination shell $i$, normalized by the supercell volume $V$. Due 7 to the volume normalization, bond energy densities can be discussed independent of 8 the supercell size.

$$
\Omega=\frac{\sum_{i} \int_{-\infty}^{\varepsilon_{f}}-p \operatorname{COH} P_{i}(E) d E}{V}
$$

\subsection{Synthesis}

All thin film metallic glasses were synthesized by physical vapor deposition. For the sputtering process elemental targets were mounted in an ultrahigh-vacuum system, in which up to four targets can be installed. The magnetrons were tilted $19^{\circ}$ normal to the substrate. The target to substrate distance was fixed to $10 \mathrm{~cm}$ for all targets. All metals were sputtered employing separate direct current power supplies, whereas B was sputtered employing a radio frequency power supply. The base pressure of the system was below $6 \cdot 10^{-5} \mathrm{~Pa}$. Ar was used as a sputtering gas at a working pressure of 0.4 Pa. No intentional heating was employed during deposition. Film thickness was at least $3 \mu \mathrm{m}$. For $\mathrm{Co}, \mathrm{Fe}$ and $\mathrm{Y}$ targets power densities in the range of 1.1-2.1, 0.71.2 and $0.1-1.7 \mathrm{~W} / \mathrm{cm}^{2}$ were employed, respectively. At the $\mathrm{B}$ target the power density was kept constant at $8.7 \mathrm{~W} / \mathrm{cm}^{2}$. For mechanical testing single-crystal Si (001) wafers with a diameter of $50.8 \mathrm{~mm}$ were used as a substrate. For the high energy X-ray diffraction experiments thin film powders were synthesized by 
1 employing polycrystalline sodium chloride substrates. The sodium chloride was later

2 removed by rinsing with demineralized water, acetone and methanol [30].

3 The metallic glass ribbons were produced by melt spinning from a master alloy of the

4 specific composition using a single-roller melt spinner. Ingots of high elemental purity

5 (99.9\%) were remolten to $1350^{\circ} \mathrm{C}$ and injected at $30000 \mathrm{~Pa}$ onto the spinning copper

6 wheel with a wheel speed of $25 \mathrm{~m} / \mathrm{s}$. The rapidly quenched ribbons were in the

7 dimension of $5 \mathrm{~mm}$ in width, thickness of about $40 \mu \mathrm{m}$ and several $\mathrm{cm}$ in length. Due

8 to the cooling rate [31] of up to $10^{6} \mathrm{~K} / \mathrm{s}$ achieved by the melt spinning process all

9 ribbons were characterized as amorphous in the as-prepared state by X-ray 10 diffraction.

\subsection{Chemical and stiffness analysis}

For the chemical analysis of the prepared samples three-dimensional atom probe tomography (3D-APT) measurements were performed using a local electrode atom probe (LEAP $3000 \times$ HR, CAMECA Instruments). The APT tips were prepared using a dual-beam focused-ion beam system (FIB, FEI Helios Nanolab 600i), employing a standard lift-out procedure [32]. The final shaping was performed with low energy (5 $\mathrm{keV}$ ) to prevent $\mathrm{Ga}$ implantation. The APT measurements were performed in voltage mode at a base temperature of $60 \mathrm{~K}, 200 \mathrm{kHz}$ pulse repetition rate, $15 \%$ pulse fraction and $0.5 \%$ target evaporation rate. The APT data were analyzed and evaluated using the software IVAS 3.6.8 (CAMECA Instruments) showing the compositions and their chemical homogeneity.

The reduced Young's modulus was measured employing the Oliver and Pharr method [33]. A depth-sensing nanoindenter (Hysitron TribolndenterTM) equipped with a Berkovich indenter tip with a tip radius of $100 \mathrm{~nm}$ was used. The results were averaged over 24 indentations. The maximum depth corresponds to less than $10 \%$ of 
1 the thin film thickness. To obtain Young's modulus the Poisson's ratio of the

2 corresponding density functional theory based calculations was employed. The bulk

3 modulus was obtained employing

$$
B=\frac{E}{3(1-2 v)}
$$

4 where the bulk modulus, Young's modulus and Poisson's ratio are denoted by $B, E$ 5 and $v$, respectively.

6

$7 \quad$ 2.4. Synchrotron real space topology analysis

8 The thin film powder samples were analyzed at the high resolution powder diffraction 9 beamline P02.1 (DESY, Hamburg, Germany). The thin film powder was put into a 10 quartz capillary with a wall thickness of $20 \mu \mathrm{m}$ with a diameter of $1 \mathrm{~mm}$ and 11 illuminated with a monochromatic photon beam with a wavelength of $0.2072 \AA$. A two dimensional plate detector Perkin Elmer 1621 was used to record diffracted photons. The sample to detector distance was fixed to $30.8 \mathrm{~cm}$, which results in a maximum wave vector of $16 \AA^{-1}$. The beam size was 0.7 by $0.7 \mathrm{~mm}$. For integration of the twodimensional patterns the FIT2D software package [34] was used. The integrated data were corrected for background, fluorescence contribution, sample absorption and 17 inelastic scattering. From the total structure factor the reduced pair distributions functions were obtained through a sine Fourier transform algorithm [7].

\section{Results and discussion}

3.1. Valence electron density

To begin, the usefulness of the valence electron density as a design guideline is examined for metalloid metallic glasses with a bulk modulus above $200 \mathrm{GPa}$. We use 
1 available literature data, our experimental values and data from density functional

2 theory based simulations. References to literature data are compiled within Table 1.

3 Figure 1 shows the bulk modulus as a function of valence electron density according

4 to equation 1 [13]. Figure 1 also contains our DFT and experimental data, colored in

5 green and red, respectively. Metalloid metallic glasses are denoted by full rectangular

6 symbols, whereas non-metalloid metallic glasses are denoted by full triangular

7 symbols. The metalloid metallic glasses exhibit an overall higher bulk modulus

8 compared to non-metalloid metallic glasses. The significant difference is the covalent

9 contribution to the bond character of metalloid metallic glasses [6]. The linear 10 dependence between valence electron density and bulk modulus is evaluated by the 11 Pearson correlation coefficient [35] $r$, which can be expressed in a general form as

$$
r=\frac{\sum_{i=1}^{n}\left(x_{i}-\bar{x}\right)\left(y_{i}-\bar{y}\right)}{\sqrt{\sum_{i=1}^{n}\left(x_{i}-\bar{x}\right)^{2}} \sqrt{\sum_{i=1}^{n}\left(y_{i}-\bar{y}\right)^{2}}}
$$

12 where $n, x, y, \bar{x}$ and $\bar{y}$ denotes the number of systems evaluated, the abscissa of system $i$, the ordinate of system $i$ and the mean values for all systems, respectively. The linear correlation between bulk modulus and valence electron density of metalloid and non-metalloid metallic glasses is characterized by significant scatter as quantified by the corresponding linear correlation factor (Pearson's $r$ ) values of 0.610 and 0.613 , respectively. Furthermore, two different slopes for the linear fits of the metalloid metallic glasses and non-metalloid metallic glasses are observed. Hence, the results from figure 1 are in agreement with literature reports stating that valence electron density as an alloying guideline is limited to metallic glasses without significant covalent contributions to the overall bond character [13].

22 Evaluating the valence electron density as design guideline for ultra-stiff metallic glasses reveals that it is imperative for knowledge based design to identify the origin 24 of the ultrahigh stiffness in metallic glasses. Hence, we employ a correlative 
1 experimental and theoretical approach, where we evaluate two Co-Fe-Y-B melt spun

2 metallic glasses synthesized with an approximate cooling rate [31] of up to $10^{6} \mathrm{~K} / \mathrm{s}$,

3 three thin film Co-Fe-Y-B metallic glasses synthesized with an approximate cooling

4 rate [36] of $10^{15} \mathrm{~K} / \mathrm{s}$ and three simulated Co-Fe-Y-B metallic glasses quenched with

5 an infinite cooling rate with increasing $B$ to $Y$ ratios from 1.8 to 10.2. We have

6 devised this research strategy to probe the significance of different processing

7 techniques for the bulk modulus of metallic glasses. We expect variations in the B to

$8 \quad \mathrm{Y}$ ratio to change molar density and stiffness significantly as $\mathrm{B}$ forms strong covalent

9 bonds [6, 7], but has a small ionic radius of $0.98 \AA$ compared to $Y$ [15], which in turn gives rise to metallic bonds and exhibits a larger ionic radius of $1.80 \AA$ [15].

\subsection{Comparison of stiffness and short range order between simulation and} experiment

To identify a criterion that reflects the origin of the ultrahigh stiffness in both, metalloid and non-metalloid metallic glasses, we first critically examine the calculated data by comparing it to experimentally obtained stiffness and short range order data. Then we analyze the simulated glasses by means of electronic structure and detailed topology analysis.

The bulk modulus as a function of $B$ to $Y$ ratio for all eight Co-Fe- $Y-B$ glasses is depicted in figure 2. Here the bulk modulus is chosen as a measure for the stiffness of the glasses. For the simulations, the chemical compositions of the metallic glass thin films are chosen for comparison purposes. There is good agreement with a maximum error of $7.5 \%$ in bulk modulus between thin films and simulated metallic glasses of the same chemical composition. Furthermore, it can be observed that with increasing $B$ to $Y$ ratio from 1.8 to 10.2 the bulk modulus increases, being independent of the synthesis technique applied. The glass with the lowest stiffness of 
$1149 \mathrm{GPa}$ is the simulated $\mathrm{Co}_{42.6} \mathrm{Fe}_{25.2} \mathrm{Y}_{11.3} \mathrm{~B}_{20.9}$ glass with a $\mathrm{B}$ to $\mathrm{Y}$ ratio of 1.8,

2 whereas the melt spun $\mathrm{CO}_{42.2} \mathrm{Fe}_{24.3} \mathrm{Y}_{3.0} \mathrm{~B}_{30.5}$ metallic glass with a $\mathrm{B}$ to $\mathrm{Y}$ ratio of 10.2

3 exhibits the highest bulk modulus of $201 \mathrm{GPa}$. The observed increase in stiffness

4 with increasing $B$ content is in agreement with reported literature on other Co-B

5 based metallic glasses [6, 37].

6 Figure 3 shows the experimentally obtained and simulated reduced pair distribution

7 functions as solid lines and open symbols, respectively. The reduced pair distribution

8 functions are depicted within a range between 1 to $10 \AA$, with equally spaced offsets

9 in the vertical direction for better clarity. From bottom to top the $B$ to $Y$ ratio increases. For the glass with the lowest $B$ to $Y$ ratio of 1.8 the first coordination shell is between 1.9 to $3.4 \AA$. With increasing $B$ to $Y$ ratio the/ coordination shell-width decreases to between 1.8 and $3.2 \AA$. The main amplitude can be attributed to the $(\mathrm{Co}, \mathrm{Fe})-(\mathrm{Co}, \mathrm{Fe})$ bond population. The shoulder to the right of the main amplitude can be attributed to the presence of $(\mathrm{Co}, \mathrm{Fe})-\mathrm{Y}$ bonds, while the small amplitude to the left of the main peak can be attributed to ( $\mathrm{Co}, \mathrm{Fe})-\mathrm{B}$ bonds. The experimentally obtained and simulated reduced pair/distribution functions show good agreement in terms of peak position and relative amplitudes, signifying that the topology obtained in experiment and theory is consistent.

At higher $B$ to $Y$ ratios or lower $Y$ contents the amplitude of the shoulder to the right of the $(\mathrm{Co}, \mathrm{Fe})-(\mathrm{Co}, \mathrm{Fe})$ bond population decreases, due to the decrease in the $(\mathrm{Co}, \mathrm{Fe})-\mathrm{Y}$ bond population. It is clear that at lower $\mathrm{Y}$ content and hence higher $\mathrm{B}$ content the population density of $Y$ bonds decreases, while the population density of $B$ bonds should increase. This is precisely what we observe: The population density of $(\mathrm{Co}, \mathrm{Fe})-\mathrm{B}$ bonds to the left of the $(\mathrm{Co}, \mathrm{Fe})-(\mathrm{Co}, \mathrm{Fe})$ bond population increases, with increasing $B$ to $Y$ ratio. This increase in amplitude can be attributed to an increase in $(\mathrm{Co}, \mathrm{Fe})-\mathrm{B}$ bond population density with increasing $\mathrm{B}$ content. The increase in 
1 (Co,Fe)-B bond population density is consistent with the observed increase in bulk

2 modulus, see figure 2. Figure 3b,c shows atomic configurations of the $3 \mathrm{Co}_{41.7} \mathrm{Fe}_{23.5} \mathrm{Y}_{3.5} \mathrm{~B}_{31.3}$ and $\mathrm{Co}_{42.6} \mathrm{Fe}_{25.2} \mathrm{Y}_{11.3} \mathrm{~B}_{20.9}$ with the highest and lowest boron 4 content of the simulated metallic glasses. Co, Fe, Y and B atoms are colored in dark 5 blue, light blue, orange and green, respectively. Within the atomic configurations 6 (Co,Fe)-B bonds smaller than $2.2 \AA$ are displayed. It can be observed that the $7 \quad \mathrm{Co}_{41.7} \mathrm{Fe}_{23.5} \mathrm{Y}_{3.5} \mathrm{~B}_{31.3}$ metallic glass exhibits a higher metal to boron bond density as 8 the $\mathrm{CO}_{42.6} \mathrm{Fe}_{25.2} \mathrm{Y}_{11.3} \mathrm{~B}_{20.9}$ metallic glass, which is consistent with the reduced pair 9 distribution function analysis of figure 3a. In literature strong metal to metalloid hybridization, associated with an increase in bond energy is proposed as the cause for the increase in stiffness observed for Co-B based glasses with increasing $B$ content $[6,7,30,37-39]$. From figure 3 we learn that the experimentally obtained short range order data from high energy X-ray diffraction and the predicted data are consistent. Also, good agreement between the elastic properties determined by experiment and theory is obtained, as presented in figure 2. The short range order analysis provides evidence that with increasing B content the metal to metalloid population density increases. Hence, the question remains, if the rise in stiffness with increasing boron content can primarily be attributed to the augmentation in bond energy and/or bond density. Therefore, we next evaluate the electronic structure of Co-Fe-Y-B metallic glasses regarding bond energy and bond density.

\subsection{Bond energy and topology analysis}

Figure 4 compares the relative change in bulk modulus, Co-B bond energy, Co-Co bond energy, average bond energy, coordination number and molar density for $\mathrm{Co}_{45.2} \mathrm{Fe}_{23.4} \mathrm{Y}_{7.0} \mathrm{~B}_{24.3}$ and $\mathrm{Co}_{41.7} \mathrm{Fe}_{23.5} \mathrm{Y}_{3.5} \mathrm{~B}_{31.3}$ with respect to the $\mathrm{Co}_{42.6} \mathrm{Fe}_{25.2} \mathrm{Y}_{11.3} \mathrm{~B}_{20.9}$ metallic glass. To evaluate the individual bond energy we have integrated the crystal 
1 orbital Hamilton population (COHP), which provides information on the bond energy

2 and according to Deringer et al. [40] "hints towards" the bond strength. Through this

3 electronic structure analysis we investigate the influence of increasing $B$ to $Y$ ratios in

4 Co-Fe-Y-B metalloid metallic glasses on bulk modulus.

5 The bar charts on the left and on the right side of figure 4 show the comparison for

$6 \mathrm{CO}_{45.2} \mathrm{Fe}_{23.4} \mathrm{Y}_{7.0} \mathrm{~B}_{24.3}$ and $\mathrm{Co}_{41.7} \mathrm{Fe}_{23.5} \mathrm{Y}_{3.5} \mathrm{~B}_{31.3}$ simulated metallic glass, respectively.

7 The relative increase in bulk modulus as the $B$ to $Y$ ratio is increased from 1.8 to 3.5

8 and 1.8 to 8.9 is 11.1 and $21.6 \%$, respectively. We first discuss the relative change

9 for $\mathrm{CO}_{45.2} \mathrm{Fe}_{23.4} \mathrm{Y}_{7.0} \mathrm{~B}_{24.3}$ compared to $\mathrm{Co}_{42.6} \mathrm{Fe}_{25.2} \mathrm{Y}_{11.3} \mathrm{~B}_{20.9}$ metallic glass. Even though the bulk modulus increases, the Co-B and Co-Co bond energy decreases by 0.7 and 36.9\%. It has been reported in literature that an increase in bond distance causes bond weakening [41]. Hence, the decrease in Co-Co bond energy is in agreement with literature data on combinatorial grown Co-Zr-Ta-B metallic glass thin films [37], which reports that as the B content increases from 26.4-32.7 at.\%, the Co-Co and $\mathrm{Zr}$ Zr first order bond distances increase by $1 \%$, implying a boron induced weakening of metallic bonds [37]. Even though the relative decrease in Co-Co bond energy is $36.9 \%$, due to a large fraction of metal to metalloid bonds the average bond energy decreases by only $1.3 \%$. What can be observed, however, is that the coordination number increases by $5.7 \%$, which can be understood by considering the decrease in atomic size by replacing $Y$ with $B$ [15]. The increase in coordination number goes along with an increase in molar density of $7.8 \%$. Based on the combined topological and electronic structure analysis the B induced increase in bulk modulus can be rationalized by an increase in coordination number and molar density rather than individual bond energy.

Comparing $\mathrm{Co}_{41.7} \mathrm{Fe}_{23.5} \mathrm{Y}_{3.5} \mathrm{~B}_{31.3}$ with a $\mathrm{B}$ to $\mathrm{Y}$ ratio of 8.9 with $\mathrm{Co}_{42.6} \mathrm{Fe}_{25.2} \mathrm{Y}_{11.3} \mathrm{~B}_{20.9}$, which exhibits a B to $\mathrm{Y}$ ratio of 1.8 , an increase in Co-B bond energy by $5.5 \%$ is 
1 observed. On the other hand the Co-Co bond energy decreases by $63.3 \%$. However,

2 on average the bond energy increases by $2.9 \%$. The coordination number and molar

3 density increase by 12.5 and $16.0 \%$, respectively. What can be learned from the

4 relative comparison of the simulated Co-Fe-Y-B metallic glasses is that as the $B$ to $Y$

5 ratio from is increased from 1.8 to 8.9 the average bond energy increases by up to

$62.9 \%$, whereas the molar density increases by up to $16.0 \%$. The increase in molar

7 density is induced by an increase in coordination number. Hence, from the electronic

8 structure analysis it is inferred that the B induced increase in bulk modulus is

9 dominated by an increase in molar density of strongly bonded metal to metalloid

bonds. This is in agreement with the experimentally observed increase in population

density of strongly bonded bonds in figure 3. To understand/the influence of average bond energy, bond density and bond energy density on bulk modulus in general, nine metallic glasses including six metalloid containing glasses and three non-metalloid glasses are further examined.

\subsection{Effect of average bond energy, bond density and bond energy density on bulk} modulus for metallic glasses in general

The bulk modulus values as a function of average bond energy, bond density and bond energy density, obtained from density functional theory based simulations are shown in figure 5a-c. Positive values for bond energy and bond energy density are bonding contributions, whereas negative values represent antibonding contributions. All glasses studied exhibit on average bonding contributions. Figure $5 d$ summarizes the chemical composition, average bond energy, bond density, bond energy density, molar density, bulk modulus, shear modulus and Young's modulus for all glasses presented in figure 5a-c. Figure $5 \mathrm{a}$ reveals that the metalloid containing glasses exhibit both, high bond energy and bulk modulus. The $\mathrm{Au}_{49.0} \mathrm{Ag}_{5.5} \mathrm{Pd}_{2.3} \mathrm{Cu}_{26.9} \mathrm{Si}_{16.3}$ 
1 glass with the lowest bulk modulus of $109 \mathrm{GPa}$ possesses also the lowest average

2 bond energy of $0.16 \mathrm{eV}$. However, the $\mathrm{Co}_{33.0} \mathrm{Ta}_{3.5} \mathrm{~B}_{63.5}$ short range ordered material

3 exhibits the highest bulk modulus, yet, with a value of $0.98 \mathrm{eV}$ only the third highest

4 average bond energy of all glasses evaluated here. Hence, a linear relation with a

5 Pearson's $r$ value of 0.790 is observed between bulk modulus and average bond

6 energy. It is not surprising that no ideal linear relationship, which would correspond to

7 a Pearson's $r$ value of 1 between bulk modulus and bond energy, is observed. The

8 bulk modulus is a measure of a solid's resistance to a volume change, whereas bond

energy obtained through integration of COHP according to Deringer et al. [40] "hints

towards" bond strength. From the data in figure $5 \mathrm{a}$ we can observe that ultra-stiff metalloid metallic glasses exhibit an overall higher average bond energy than nonmetalloid metallic glasses. Furthermore, metalloid metallic glasses possess an overall higher molar density compared to non-metalloid metallic glasses, which is in agreement with literature reports on binding-energy - bond distance relationships for metals and bimetallic interfaces [42, 43] and both metallic and covalent bonds in chemisorption [44]. The $\mathrm{Co}_{33.0} \mathrm{Ta}_{3.5} \mathrm{~B}_{63.5}$ short range ordered material predicted here by density functional theory based molecular dynamics simulations exhibits a $17 \%$ higher bulk modulus than the stiffest Co-B based metallic glass reported in literature [3-7]. With $0.207 \mathrm{~mol} / \mathrm{cm}^{3} \mathrm{Co}_{33.0} \mathrm{Ta}_{3.5} \mathrm{~B}_{63.5}$ also has the highest molar density of all nine glasses studied. A linear relation with a Pearson's $r$ value of 0.931 is observed between bulk modulus and bond density. It is straightforward to recognize that with more bonds per unit volume the bulk modulus, which is a measure for the average bond stiffness per unit volume, increases, if the individual bond stiffness is not decreased. The bond density induced rise in bulk modulus is consistent with the B induced increase in Co-B bond population density in figure 3. The analysis of figure $5 a, b$ suggests that bond density exhibits a better fit to the linear relationship 
1 with bulk modulus compared to average bond energy. This observation is in

2 agreement with the topology and electronic structure comparison of Co-Fe-Y-B

3 metallic glasses from figure 4 . Figure $5 c$ reveals that the combination of average

4 bond energy and bond density, or bond energy density, provides an even better

5 linear relation with bulk modulus compared to the bulk modulus - bond density

6 relationship reflected in a Pearson's $r$ value of 0.955 . Hence, we propose that an

7 increase in average bond energy and bond density, constituting bond energy density,

8 is capable of reflecting the origin for the increase in bulk modulus. Based on the bond

9 energy density criterion we have predicted by density functional theory based

10 molecular dynamics simulations that $\mathrm{a}_{33.0} \mathrm{Ta}_{3.5} \mathrm{~B}_{63.5}$ short range ordered material

11 should have a high bulk modulus of $263 \mathrm{GPa}$.

12 Our data clearly demonstrate that the bond energy density is capable of reflecting the 13 origin of the ultrahigh stiffness in metallic glasses. Hence, we propose bond energy 14 density as the design parameter for ultra-stiff metallic glasses. We find that for 15 metallic glasses a change in chemical composition leads to a combined change in 16 average bond energy and preferred coordination number. Both chemically induced 17 changes are inherently captured by the molar density. Hence, our results suggest 18 that bond energy density is capable to rationalize the bulk modulus - molar density 19 relationship observed in literature [16]. 
1

2 For identifying the origin of ultrahigh stiffness in metallic glasses, we have studied the

3 effect of an order of magnitude increase of the $B$ to $Y$ ratio in Co-Fe-Y-B thin film and

\section{Conclusions}

melt spun metallic glasses on the elastic behavior, both theoretically and

5 experimentally. It is observed that with increasing $B$ to $Y$ ratio from 1.8 to 10.2 the

6 bulk modulus increases, which is consistent with previous reports on Co-B/based

7 metallic glasses [6, 7, 30, 37-39]. Using high energy X-ray diffraction experiments

8 combined with density functional theory based molecular dynamics simulations, it is bond energy density, reflects the origin of the elastic properties in both, metalloid and non-metalloid metallic glasses. This has enabled us to predict a $\mathrm{Co}_{33.0} \mathrm{Ta}_{3.5} \mathrm{~B}_{63.5}$ short metallic glasses suggests that the bulk modulus increases from 109 to $263 \mathrm{GPa}$ as the bond density increases from 0.33 to $0.96 \AA^{-3}$. Based on the combined experimental and theoretical data, we propose that bond energy density is capable of reflecting the origin of ultrahigh stiffness in metallic glasses including metalloid metallic glasses. Based on bond energy density, the well-known and accepted bulk modulus - molar density relationship and the limitation of the bulk modulus - valence electron density guideline can be rationalized. We propose bond energy density as a generic design criterion for stiffness in metallic glasses including metalloid metallic glasses.

The bulk modulus is one the most important properties of a structural material. However, to date there is no knowledge based criterion for designing ultra-stiff metallic glasses with a bulk modulus above $200 \mathrm{GPa}$ is lacking. We have shown the range ordered material by density functional theory based molecular dynamics 
1 simulations. It has a bond energy density of $0.94 \mathrm{eV} / \AA^{3}$ and bulk modulus of $263 \mathrm{GPa}$,

2 which is $17 \%$ greater than the stiffest Co-B based metallic glasses reported in

3 literature [3-7].

$4 \quad$ We therefore propose bond energy density as a generic design criterion for predicting

5 stiffness in metallic glasses including metalloid metallic glasses.

6

\section{$7 \quad$ Acknowledgements}

8 The authors acknowledge support by the German National Science Foundation

9 (DFG) within the SPP-1594. Simulations were performed with computing resources

10 granted by JARA-HPC from RWTH Aachen University under project JARA0131.

11 Parts of this research were carried out at the light source PETRA III (beamline P02.1)

12 at DESY, a member of the Helmholtz Association (HGF). WJC also acknowledges the support of the EPSRC/Rolls-Royce Strategic Partnership (EP/M005607/1). 
- Metalloid metallic glasses (DFT)

- Metalloid metallic glasses (Syn)

$\Delta \quad$ Non-metalloid metallic glasses (DFT)

$\Delta \quad$ Non-metalloid metallic glasses (Syn)

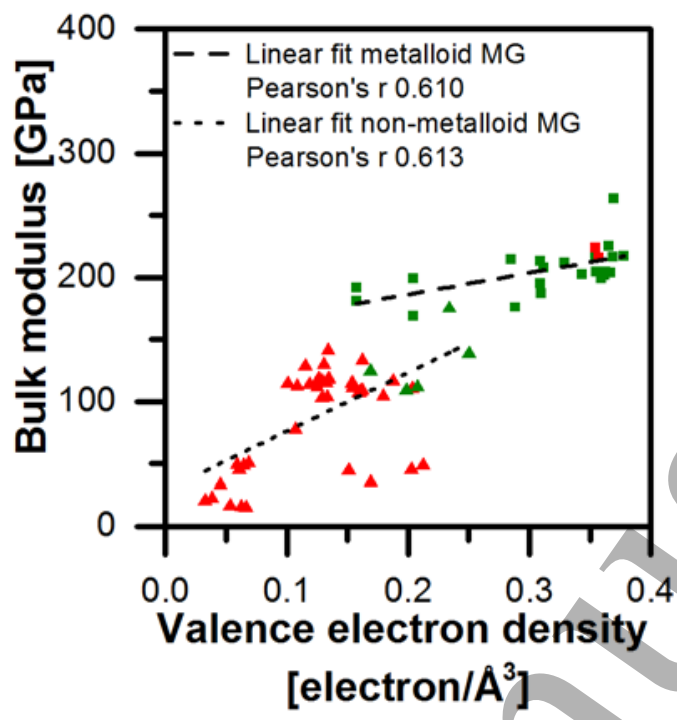

Figure 1. Bulk modulus - valence electron density relationship for metallic glasses.

3 The full rectangular and triangular symbols represent metalloid and non-metalloid 4 metallic glasses (MG), respectively. Data from density functional theory (DFT) based

5 simulations are colored green, whereas data from synthesized (Syn) bulk metallic 6 glasses are colored in red. 


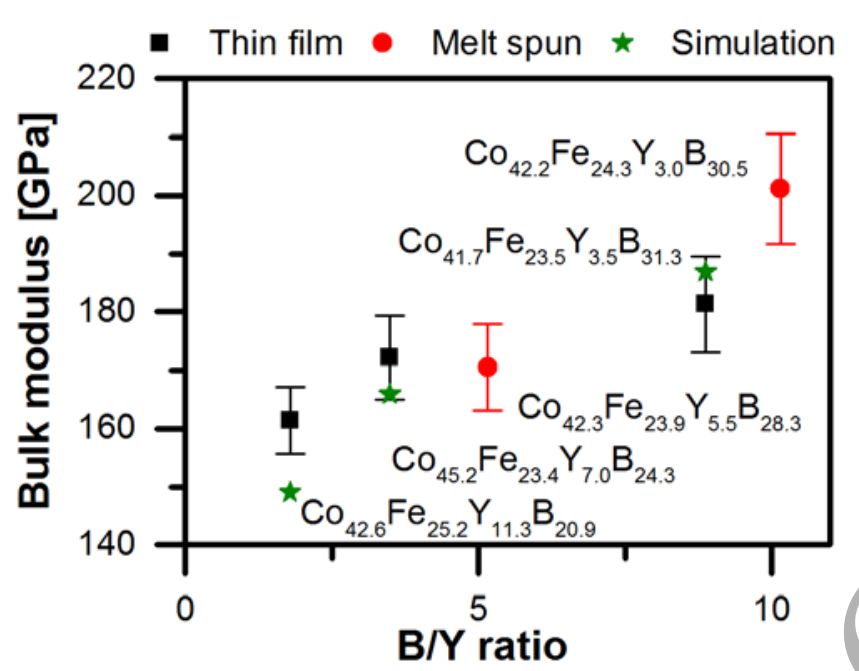

1

Figure 2. Measured and calculated bulk modulus as a function of $B$ to $Y$ ratio of Co3 Fe-Y-B metallic glasses. The rectangular, round and star symbols represent data 4 obtained from thin films, melt spun alloys and simulations, respectively. An increase 5 in bulk modulus is observed irrespective of the synthesis technique. The top three 6 images, from left to right illustrate co-magnetron sputtering, melt spinning and density 7 functional theory based molecular dynamics simulations, respectively. 


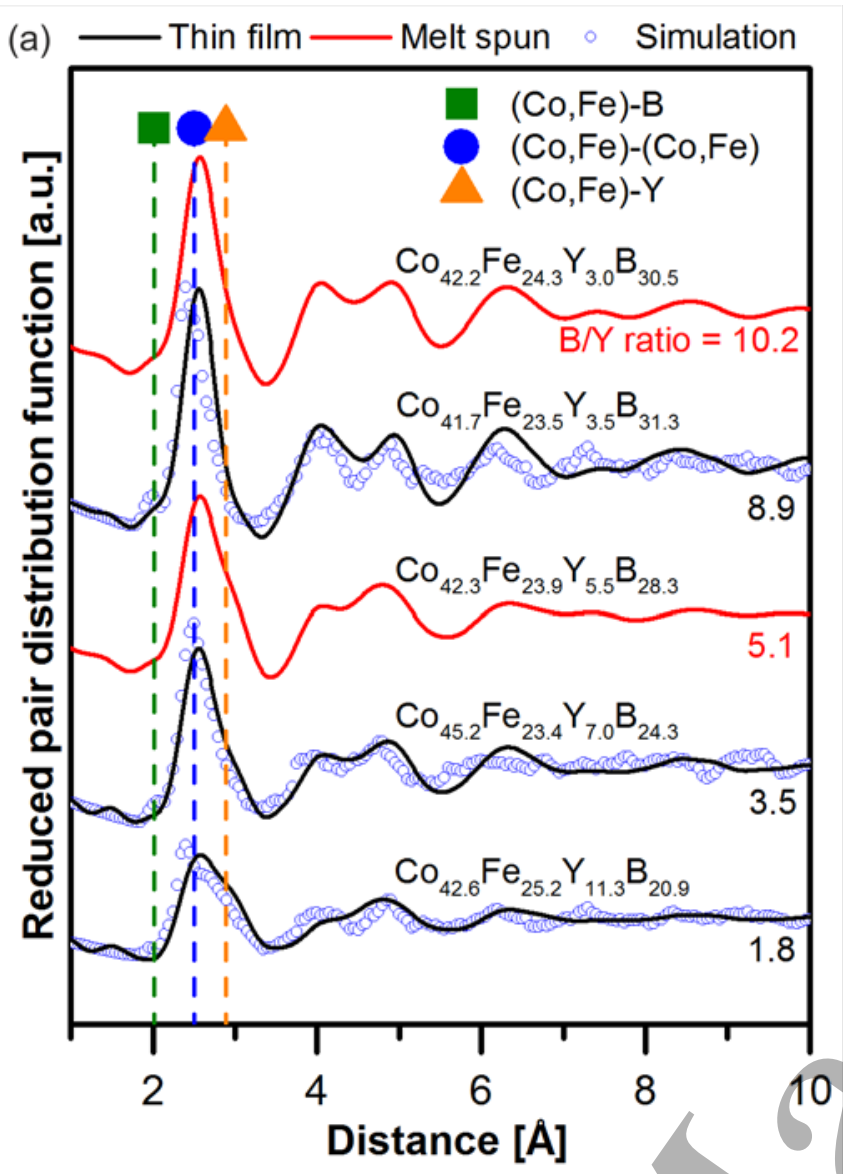

(b) $\quad \mathrm{Co}_{41.7} \mathrm{Fe}_{23.5} \mathrm{Y}_{3.5} \mathrm{~B}_{31.3}$

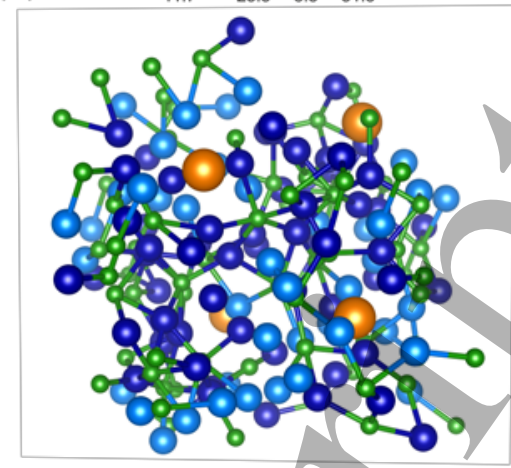

(c)

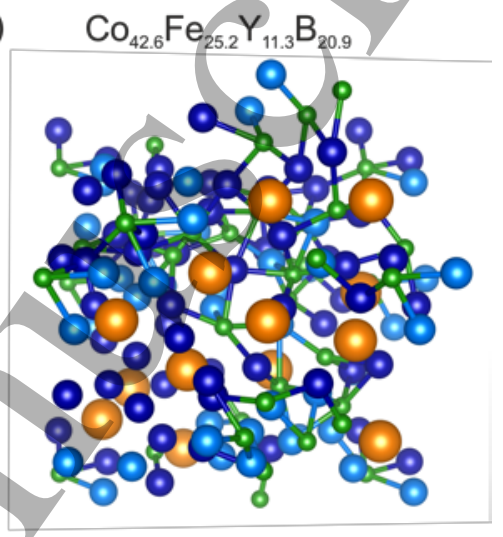

\section{Distance $[A]$}

Figure 3. Reduced pair distribution functions for melt spun alloys, thin films and 3 simulations are depicted in the range of 1 to $10 \AA$. (a) There is good agreement for 4 the reduced pair distribution functions in terms of peak position and relative 5 amplitudes between experiments and simulations of identical compositions. With 6 increasing $Y$ content the $(\mathrm{Co}, \mathrm{Fe})-\mathrm{Y}$ bond population increases, whereas for 7 increasing $\mathrm{B}$ content the ( $\mathrm{Co}, \mathrm{Fe})-\mathrm{B}$ bond population increases. Atomic configuration 8 snapshots of the $\mathrm{Co}_{41.7} \mathrm{Fe}_{23.5} \mathrm{Y}_{3.5} \mathrm{~B}_{31.3}$ and $\mathrm{Co}_{42.6} \mathrm{Fe}_{25.2} \mathrm{Y}_{11.3} \mathrm{~B}_{20.9}$ metallic glasses are 9 shown in (b) and (c), respectively. $\mathrm{Co}, \mathrm{Fe}, \mathrm{Y}$ and $\mathrm{B}$ atoms are colored in dark blue, 10 light blue, orange and green, respectively. 
2 Figure 4. Comparison in terms of bulk modulus, Co-B bond energy, Co-Co bond 3 energy, average bond energy, coordination number and molar density for Co-Fe-Y-B 4 metallic glasses with increasing $B$ to $Y$ ratio from 1.8 to 8.9. With increasing $B$ content 5 the coordination number increases, which goes in hand with an increase in molar 6 density. This increase in molar density and coordination number, which infers an 7 increase in bond density, dominates the increase in average bond energy.

$$
\text { Reference to } \mathrm{Co}_{42.6} \mathrm{Fe}_{25.2} \mathrm{Y}_{11.3} \mathrm{~B}_{20.9}, \mathrm{~B} / \mathrm{Y}=1.8
$$

Relative change in

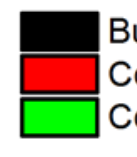

Bulk modulus

Co-B bond energy Co-Co bond energy Coordination number Molar density

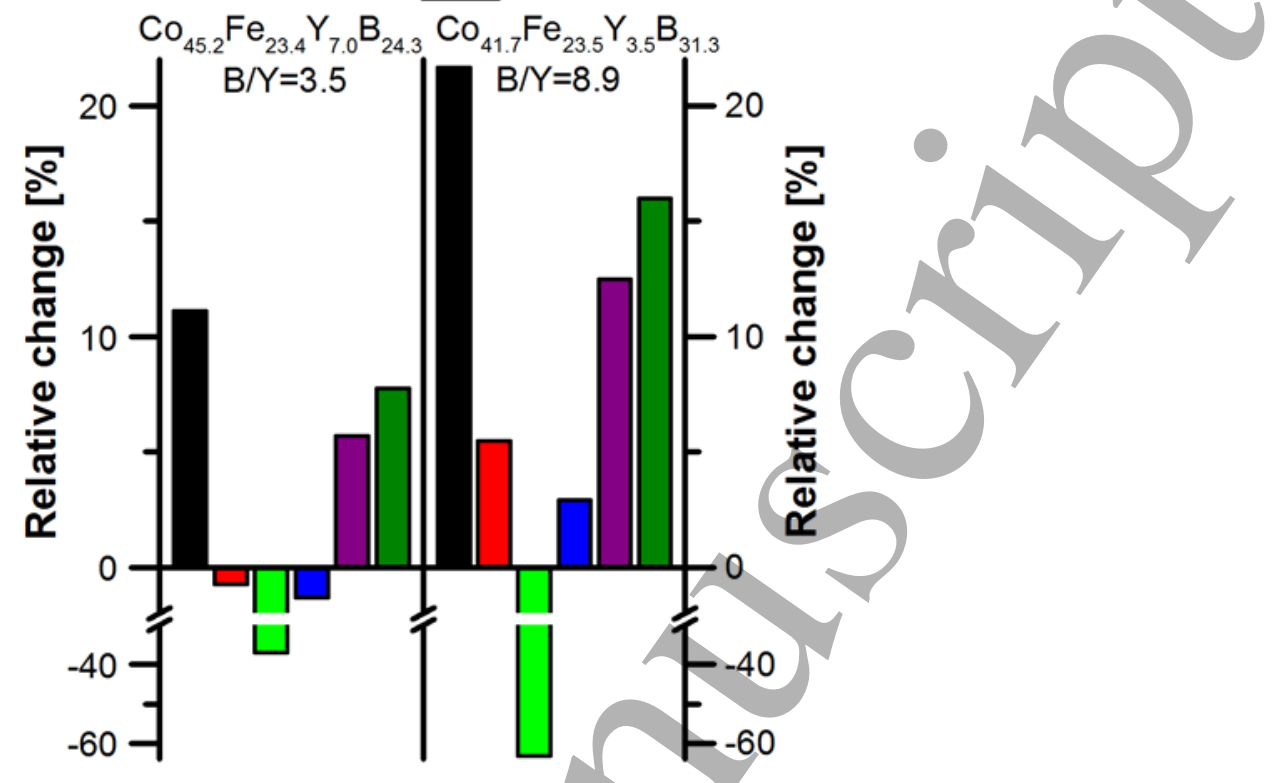




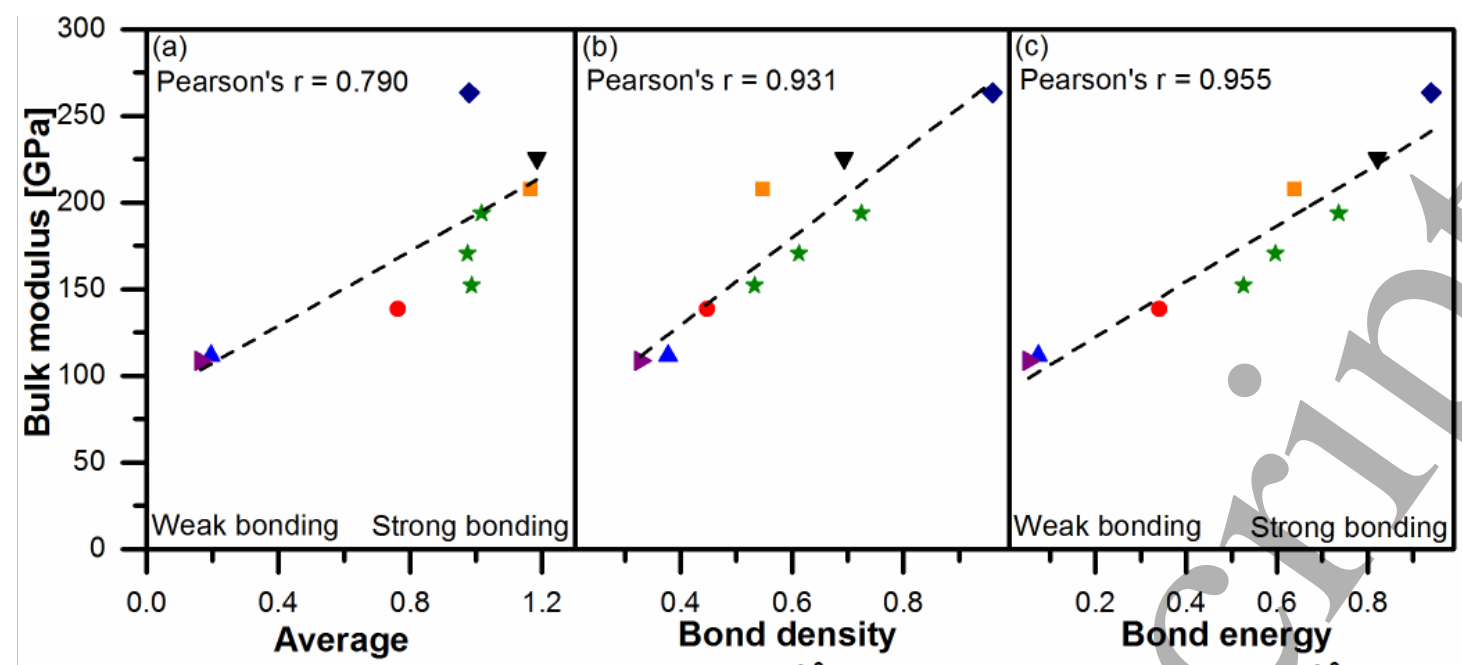

(d)

$\left[1 / A^{3}\right]$

density $\left[\mathrm{eV} / \mathrm{A}^{3}\right]$

\begin{tabular}{|c|c|c|c|c|c|c|c|}
\hline Composition & $\begin{array}{c}\text { Average } \\
\text { bond energy } \\
\text { eV }\end{array}$ & $\begin{array}{c}\text { Bond } \\
\text { density } \\
1 / \AA^{3} \\
\end{array}$ & $\begin{array}{c}\text { Bond energy } \\
\text { density } \\
\text { eVIA } \AA^{3}\end{array}$ & $\begin{array}{c}\text { Molar density } \\
\mathrm{mol} / \mathrm{cm}^{3}\end{array}$ & $\begin{array}{c}\mathrm{B} \\
\mathrm{GPa} \\
\end{array}$ & $\begin{array}{c}\mathrm{G} \\
\mathrm{GPa}\end{array}$ & $\begin{array}{c}\mathrm{E} \\
\mathrm{GPa} \\
\end{array}$ \\
\hline$-\mathrm{Co}_{33.0} \mathrm{Ta}_{3.5} \mathrm{~B}_{63.5}$ & 0.98 & 0.96 & 0.94 & 0.207 & 263 & 118 & 307 \\
\hline$\star \mathrm{Co}_{41.7} \mathrm{Fe}_{23.5} \mathrm{Y}_{3.5} \mathrm{~B}_{31.3}$ & 1.02 & 0.72 & 0.74 & 0.163 & 194 & 82 & 215 \\
\hline$\star \mathrm{Co}_{45.2} \mathrm{Fe}_{23.4} \mathrm{Y}_{7.0} \mathrm{~B}_{24.3}$ & 0.97 & 0.61 & 0.60 & 0.148 & 171 & 71 & 188 \\
\hline$\star \mathrm{Co}_{42.6} \mathrm{Fe}_{25.2} \mathrm{Y}_{11.3} \mathrm{~B}_{20.9}$ & 0.98 & 0.53 & 0.53 & 0.137 & 152 & 63 & 165 \\
\hline$\nabla \mathrm{Co}_{58.4} \mathrm{Fe}_{7.0} \mathrm{~B}_{34.6}$ & 1.18 & 0.69 & 0.82 & 0.181 & 225 & 92 & 244 \\
\hline$\Delta \mathrm{Cu}_{70} \mathrm{Zr}_{30}$ & 0.20 & 0.38 & 0.07 & 0.104 & 112 & 36 & 98 \\
\hline - $\mathrm{Co}_{65} \mathrm{Zr}_{35}$ & 0.76 & 0.45 & 0.34 & 0.113 & 138 & 39 & 106 \\
\hline$\square \mathrm{Co}_{42.0} \mathrm{Fe}_{13.2} \mathrm{Zr}_{10.7} \mathrm{Ta}_{6.6} \mathrm{~B}_{27.5}$ & 1.17 & 0.55 & 0.64 & 0.150 & 208 & 100 & 258 \\
\hline$-\mathrm{Au}_{49.0} \mathrm{Ag}_{5.5} \mathrm{Pd}_{2.3} \mathrm{Cu}_{26.9} \mathrm{Si}_{16.3}$ & 0.16 & 0.33 & 0.05 & 0.096 & 109 & 29 & 81 \\
\hline
\end{tabular}

Figure 5. Comparison for metallic glasses in general. (a-c) Bulk modulus as a

3 function of average bond energy, bond density and bond energy density, obtained

4 from density functional theory based simulations, are presented, respectively.

5 Bonding contributions are represented by positive values. (d) Summary of chemical

6 composition, average bond energy, bond density, bond energy density, molar

7 density, bulk modulus $B$, shear modulus $G$ and Young's modulus $E$ for all glasses

8 presented in Figure $5 \mathrm{a}-\mathrm{c}$. 
1 Table 1. Molar density, molar volume, bulk modulus, shear modulus and Young's

2 modulus data for the metallic glasses shown figure 1.

\begin{tabular}{|c|c|c|c|c|c|c|}
\hline Chemical composition & $\begin{array}{c}\text { Molar } \\
\text { density } \\
\mathrm{mol} / \mathrm{cm}^{3}\end{array}$ & $\begin{array}{c}\text { Molar } \\
\text { volume } \\
\mathrm{cm}^{3} / \mathrm{mol}\end{array}$ & $\begin{array}{c}\text { Bulk } \\
\text { modulus } \\
\text { GPa }\end{array}$ & $\begin{array}{c}\text { Shear } \\
\text { modulus } \\
\text { GPa }\end{array}$ & $\begin{array}{c}\text { Young's } \\
\text { modulus } \\
\text { GPa }\end{array}$ & \\
\hline $\mathrm{Co}_{33.0} \mathrm{Ta}_{3.5} \mathrm{~B}_{63.5}$ & 0.207 & 4.83 & 263 & 118 & 307 & This work \\
\hline $\mathrm{Co}_{58.4} \mathrm{Fe}_{7.0} \mathrm{~B}_{34.6}$ & 0.181 & 5.53 & 225 & 92 & 244 & This work \\
\hline $\mathrm{Co}_{43.5} \mathrm{Fe}_{20} \mathrm{Ta}_{6.1} \mathrm{~B}_{28.7} \mathrm{~N}_{1.7}$ & 0.160 & 6.26 & 195 & 69 & 185 & This work \\
\hline $\mathrm{Co}_{43.5} \mathrm{Fe}_{20} \mathrm{Ta}_{6.1} \mathrm{~B}_{21.7} \mathrm{~N}_{8.7}$ & 0.161 & 6.20 & 199 & 76 & 202 & This work \\
\hline $\mathrm{Co}_{43.5} \mathrm{Fe}_{20} \mathrm{Ta}_{6.1} \mathrm{~B}_{15.6} \mathrm{~N}_{14.8}$ & 0.157 & 6.38 & 192 & 71 & 190 & This work \\
\hline $\mathrm{Co}_{43.5} \mathrm{Fe}_{10.4} \mathrm{Ta}_{6.1} \mathrm{~B}_{30.4} \mathrm{Y}_{9.6}$ & 0.145 & 6.88 & 176 & 74 & 195 & This work \\
\hline $\mathrm{Co}_{43.5} \mathrm{Fe}_{13.9} \mathrm{Ta}_{6.1} \mathrm{~B}_{30.4} \mathrm{Y}_{6.1}$ & 0.152 & 6.58 & 187 & 73 & 193 & This work \\
\hline $\mathrm{Co}_{43.5} \mathrm{Fe}_{10.4} \mathrm{Ta}_{6.1} \mathrm{~B}_{30.4} \mathrm{Zr}_{9.6}$ & 0.150 & 6.66 & 208 & 100 & 258 & This work \\
\hline $\mathrm{Co}_{43.5} \mathrm{Fe}_{13.9} \mathrm{Ta}_{6.1} \mathrm{~B}_{30.4} \mathrm{Zr}_{6.1}$ & 0.155 & 6.44 & 212 & 102 & 263 & This work \\
\hline $\mathrm{Co}_{43.5} \mathrm{Fe}_{20} \mathrm{Ta}_{6.1} \mathrm{~B}_{21.7} \mathrm{O}_{8.7}$ & 0.146 & 6.86 & 169 & 62 & 166 & This work \\
\hline $\mathrm{Co}_{43.5} \mathrm{Fe}_{20} \mathrm{Ta}_{6.1} \mathrm{~B}_{15.6} \mathrm{O}_{14.8}$ & 0.154 & 6.50 & 181 & 65 & 174 & This work \\
\hline $\mathrm{Co}_{43.5} \mathrm{Fe}_{10.4} \mathrm{Ta}_{6.1} \mathrm{~B}_{30.4} \mathrm{~W}_{9.6}$ & 0.156 & 6.43 & 219 & 84 & 224 & This work \\
\hline $\mathrm{Co}_{43.5} \mathrm{Fe}_{13.9} \mathrm{Ta}_{6.1} \mathrm{~B}_{30.4} \mathrm{~W}_{6.1}$ & 0.161 & 6.22 & 218 & 82 & 220 & This work \\
\hline $\mathrm{Co}_{43.5} \mathrm{Fe}_{20} \mathrm{Ta}_{6.1} \mathrm{~B}_{28.7} \mathrm{C}_{1.7}$ & 0.163 & 6.15 & 202 & 82 & 217 & This work \\
\hline $\mathrm{Co}_{43.5} \mathrm{Fe}_{20} \mathrm{Ta}_{6.1} \mathrm{~B}_{21.7} \mathrm{C}_{8.7}$ & 0.166 & 6.04 & 213 & 84 & 224 & This work \\
\hline $\mathrm{Co}_{43.5} \mathrm{Fe}_{20} \mathrm{Ta}_{6.1} \mathrm{~B}_{15.6} \mathrm{C}_{14.8}$ & 0.166 & 6.01 & 215 & 84 & 222 & This work \\
\hline $\mathrm{Co}_{43.5} \mathrm{Fe}_{18.3} \mathrm{Ta}_{6.1} \mathrm{~B}_{30.4} \mathrm{Nb}_{1.7}$ & 0.162 & 6.16 & 204 & 82 & 216 & This work \\
\hline $\mathrm{Co}_{43.5} \mathrm{Fe}_{13.9} \mathrm{Ta}_{6.1} \mathrm{~B}_{30.4} \mathrm{Nb}_{6.1}$ & 0.154 & 6.48 & 199 & 75 & 201 & This work \\
\hline $\mathrm{Co}_{43.5} \mathrm{Fe}_{10.4} \mathrm{Ta}_{6.1} \mathrm{~B}_{30.4} \mathrm{Nb}_{9.6}$ & 0.153 & 6.55 & 204 & 80 & 213 & This work \\
\hline $\mathrm{Co}_{43.5} \mathrm{Fe}_{10.4} \mathrm{Ta}_{6.1} \mathrm{~B}_{30.4} \mathrm{Mo}_{9.6}$ & 0.158 & 6.32 & 217 & 87 & 230 & This work \\
\hline $\mathrm{Co}_{43.5} \mathrm{Fe}_{13.9} \mathrm{Ta}_{6.1} \mathrm{~B}_{30.4} \mathrm{Mo}_{6.1}$ & 0.162 & 6.19 & 217 & 83 & 220 & This work \\
\hline $\mathrm{Co}_{43.5} \mathrm{Fe}_{13.9} \mathrm{Ta}_{6.1} \mathrm{~B}_{30.4} \mathrm{Hf}_{6.1}$ & 0.157 & 6.37 & 202 & 87 & 229 & This work \\
\hline $\mathrm{Co}_{43.5} \mathrm{Fe}_{10.4} \mathrm{Ta}_{6.1} \mathrm{~B}_{30.4} \mathrm{Hf}_{9.6}$ & 0.154 & 6.50 & 204 & 82 & 217 & This work \\
\hline $\mathrm{Co}_{56} \mathrm{Ta}_{9} \mathrm{~B}_{35}$ & 0.175 & 5.72 & 224 & 94 & 247 & [38] \\
\hline $\mathrm{Co}_{58} \mathrm{Ta}_{7} \mathrm{~B}_{35}$ & 0.177 & 5.65 & 216 & 92 & 241 & [38] \\
\hline $\mathrm{Cu}_{70} \mathrm{Zr}_{30}$ & 0.104 & 9.62 & 112 & 36 & 98 & This work \\
\hline $\mathrm{Co}_{65} \mathrm{Zr}_{35}$ & 0.113 & 8.83 & 138 & 39 & 106 & This work \\
\hline $\mathrm{Au}_{49.0} \mathrm{Ag}_{5.5} \mathrm{Cu}_{26.9} \mathrm{P}$ & 0.096 & 10.45 & 109 & 29 & 81 & This work \\
\hline $\mathrm{Pt}_{57.5} \mathrm{Cu}_{14.7} \mathrm{Ni}_{5.3} \mathrm{P}_{22.5}$ & 0.106 & 9.40 & 175 & 35 & 100 & This work \\
\hline $\mathrm{Pd}_{57.0} \mathrm{Al}_{23.9} \mathrm{Cu}_{11.4} \mathrm{Y}_{7.7}$ & 0.100 & 9.96 & 124 & 39 & 106 & This work \\
\hline $\mathrm{Mg}_{65} \mathrm{Cu}_{25} \mathrm{Gd}_{10}$ & 0.080 & 12.49 & 45 & 19 & 51 & {$[45,46]$} \\
\hline $\mathrm{Mg}_{65} \mathrm{Cu}_{25} \mathrm{~Tb}_{10}$ & 0.084 & 11.91 & 45 & 20 & 51 & {$[3,47]$} \\
\hline $\mathrm{Mg}_{58.5} \mathrm{Cu}_{30.5} \mathrm{Y}_{11}$ & 0.082 & 12.22 & 49 & 20 & 54 & {$[48]$} \\
\hline $\mathrm{Mg}_{57} \mathrm{Cu}_{31} Y_{6.6} \mathrm{Nd}_{5.4}$ & 0.081 & 12.39 & 48 & 21 & 54 & [48] \\
\hline $\mathrm{Mg}_{58} \mathrm{Cu}_{27} \mathrm{Y}_{10} \mathrm{Zn}_{5}$ & 0.082 & 12.20 & 45 & 21 & 55 & [49] \\
\hline $\mathrm{Mg}_{57} \mathrm{Cu}_{34} \mathrm{Nd}_{9}$ & 0.085 & 11.81 & 51 & 21 & 54 & [16] \\
\hline $\mathrm{Mg}_{64} \mathrm{Cu}_{21} \mathrm{Nd}_{15}$ & 0.073 & 13.66 & 45 & 18 & 47 & [16] \\
\hline $\mathrm{Mg}_{70} \mathrm{Zn}_{25} \mathrm{Ca}_{5}$ & 0.075 & 13.34 & 48 & 18 & 48 & [16] \\
\hline $\mathrm{Ti}_{45} \mathrm{Zr}_{20} \mathrm{Be}_{35}$ & 0.107 & 9.35 & 111 & 36 & 97 & [50] \\
\hline $\mathrm{Ti}_{45} \mathrm{Zr}_{20} \mathrm{Be}_{30} \mathrm{Cr}_{5}$ & 0.111 & 8.97 & 115 & 39 & 106 & [50] \\
\hline
\end{tabular}


Table 1. (continued)

\begin{tabular}{|c|c|c|c|c|c|c|}
\hline Chemical composition & $\begin{array}{c}\text { Molar } \\
\text { density } \\
\mathrm{mol} / \mathrm{cm}^{3}\end{array}$ & $\begin{array}{c}\text { Molar } \\
\text { volume } \\
\mathrm{cm}^{3} / \mathrm{mol}\end{array}$ & $\begin{array}{c}\text { Bulk } \\
\text { modulus } \\
\text { GPa }\end{array}$ & $\begin{array}{c}\text { Shear } \\
\text { modulus } \\
\text { GPa }\end{array}$ & $\begin{array}{c}\text { Young's } \\
\text { modulus } \\
\text { GPa }\end{array}$ & Ref. \\
\hline $\mathrm{Ti}_{40} \mathrm{Zr}_{25} \mathrm{Be}_{30} \mathrm{Cr}_{5}$ & 0.087 & 11.56 & 103 & 35 & 95 & [50] \\
\hline $\mathrm{Zr}_{65} \mathrm{Cu}_{12.5} \mathrm{Be}_{22.5}$ & 0.088 & 11.32 & 112 & 28 & 77 & [50] \\
\hline $\mathrm{Zr}_{41.2} \mathrm{Ti}_{13.8} \mathrm{Cu}_{12.5} \mathrm{Ni}_{10} \mathrm{Be}_{22.5}$ & 0.101 & 9.88 & 116 & 37 & 101 & [50] \\
\hline $\mathrm{Zr}_{46.75} \mathrm{Ti}_{8.25} \mathrm{Cu}_{7.5} \mathrm{Ni}_{10} \mathrm{Be}_{27.5}$ & 0.101 & 9.92 & 110 & 35 & 95 & [50] \\
\hline $\mathrm{Zr}_{34} \mathrm{Ti}_{15} \mathrm{Y}_{2} \mathrm{Ni}_{11} \mathrm{Cu}_{10} \mathrm{Be}_{28}$ & 0.104 & 9.57 & 114 & 41 & & [51] \\
\hline $\mathrm{Zr}_{45} \mathrm{Nb}_{8} \mathrm{Cu}_{13} \mathrm{Ni}_{4} \mathrm{Fe}_{8} \mathrm{Be}_{22}$ & 0.100 & 10.02 & 115 & 35 & 96 & [16] \\
\hline $\mathrm{Zr}_{45} \mathrm{Nb}_{10} \mathrm{Cu}_{13} \mathrm{Ni}_{2} \mathrm{Fe}_{8} \mathrm{Be}_{22}$ & 0.100 & 10.03 & 118 & 36 & 97) & [51] \\
\hline $\mathrm{Zr}_{48} \mathrm{Nb}_{8} \mathrm{Cu}_{12} \mathrm{Fe}_{8} \mathrm{Be}_{24}$ & 0.098 & 10.18 & 114 & 35 & 96 & [52] \\
\hline $\mathrm{Zr}_{45} \mathrm{Nb}_{10} \mathrm{Cu}_{13} \mathrm{Ni}_{10} \mathrm{Be}_{22}$ & 0.098 & 10.19 & 118 & 36 & 99 & [51] \\
\hline $\mathrm{Zr}_{48} \mathrm{Nb}_{8} \mathrm{Cu}_{14} \mathrm{Ni}_{12} \mathrm{Be}_{18}$ & 0.097 & 10.26 & 118 & 34 & 94 & [52] \\
\hline $\mathrm{Zr}_{65} \mathrm{Al}_{10} \mathrm{Ni}_{10} \mathrm{Cu}_{15}$ & 0.086 & 11.65 & 107 & 30 & 83 & [53] \\
\hline $\mathrm{Zr}_{61.88} \mathrm{Al}_{10} \mathrm{Ni}_{10.12} \mathrm{Cu}_{18}$ & 0.087 & 11.51 & 108 & 29 & 80 & [16] \\
\hline $\mathrm{Zr}_{64.13} \mathrm{Al}_{10} \mathrm{Ni}_{10.12} \mathrm{Cu}_{15.75}$ & 0.086 & 11.68 & 107 & 29 & 78 & [16] \\
\hline $\mathrm{Zr}_{62} \mathrm{Al}_{10} \mathrm{Ni}_{12.5} \mathrm{Cu}_{15.5}$ & 0.087 & 11.56 & 109 & 29 & 80 & [16] \\
\hline $\mathrm{Zr}_{55} \mathrm{Al}_{19} \mathrm{Co}_{19} \mathrm{Cu}_{7}$ & 0.087 & 11.44 & 115 & 38 & 102 & [54] \\
\hline $\mathrm{Zr}_{57} \mathrm{Nb}_{5} \mathrm{Cu}_{15.4} \mathrm{Ni}_{12.6} \mathrm{Al}_{10}$ & 0.088 & 11.32 & 111 & 32 & 86 & {$[3,16]$} \\
\hline $\mathrm{Zr}_{52.5} \mathrm{Ti}_{5} \mathrm{Cu}_{17.9} \mathrm{Ni}_{14.6} \mathrm{Al}_{10}$ & 0.092 & 10.84 & 114 & 32 & 89 & {$[3,16]$} \\
\hline $\mathrm{Ni}_{45} \mathrm{Ti}_{20} \mathrm{Zr}_{25} \mathrm{Al}_{10}$ & 0.104 & 9.61 & 130 & 42 & 114 & {$[54,55]$} \\
\hline $\mathrm{Ni}_{40} \mathrm{Ti}_{17} \mathrm{Zr}_{28} \mathrm{Cu}_{5} \mathrm{Al}_{10}$ & 0.103 & 9.73 & 141 & 50 & 134 & {$[54,55]$} \\
\hline $\mathrm{Cu}_{46} \mathrm{Zr}_{46} \mathrm{Al}_{8}$ & 0.097 & 10.36 & 116 & 34 & 94 & [3] \\
\hline $\mathrm{Cu}_{46} \mathrm{Zr}_{46} \mathrm{Al}_{7} \mathrm{Gd}_{1}$ & 0.096 & 10.47 & 124 & 33 & 91 & [3] \\
\hline $\mathrm{Cu}_{46} \mathrm{Zr}_{42} \mathrm{Al}_{7} \mathrm{Y}_{5}$ & 0.098 & 10.22 & 104 & 31 & 85 & [54] \\
\hline $\mathrm{Cu}_{50} \mathrm{Hf}_{43} \mathrm{Al}_{7}$ & 0.100 & 10.04 & 133 & 42 & 113 & [54] \\
\hline $\mathrm{Cu}_{57.5} \mathrm{Hf}_{27.5} \mathrm{Ti}_{15}$ & 0.107 & 9.36 & 118 & 37 & 103 & [54] \\
\hline $\mathrm{Cu}_{60} \mathrm{Zr}_{20} \mathrm{Hf}_{10} \mathrm{Ti}_{10}$ & 0.105 & 9.52 & 128 & 37 & 101 & {$[56,57]$} \\
\hline $\mathrm{Ca}_{55} \mathrm{Mg}_{25} \mathrm{Cu}_{20}$ & 0.054 & 18.38 & 23 & 11 & 28 & {$[58,59]$} \\
\hline $\mathrm{Ca}_{35} \mathrm{Cu}_{35} \mathrm{Mg}_{30}$ & 0.070 & 14.19 & 33 & 15 & 38 & [59] \\
\hline $\mathrm{Ca}_{65} \mathrm{Mg}_{8.54} \mathrm{Li}_{9.96} \mathrm{Zn}_{16.5}$ & 0.049 & 20.25 & 20 & 9 & 23 & {$[3,16]$} \\
\hline $\mathrm{Nd}_{60} \mathrm{Fe}_{20} \mathrm{Co}_{10} \mathrm{Al}_{10}$ & 0.066 & 15.18 & 47 & 19 & 51 & {$[3,60]$} \\
\hline $\mathrm{Pr}_{60} \mathrm{Cu}_{20} \mathrm{Ni}_{10} \mathrm{Al}_{10}$ & 0.065 & 15.33 & 45 & 14 & 37 & {$[3,53]$} \\
\hline $\mathrm{La}_{55} \mathrm{Cu}_{10} \mathrm{Ni}_{5} \mathrm{Co}_{5} \mathrm{Al}_{25}$ & 0.063 & 15.90 & 44 & 16 & 42 & [3] \\
\hline $\mathrm{Ce}_{70} \mathrm{Al}_{10} \mathrm{Ni}_{10} \mathrm{Cu}_{10}$ & 0.059 & 16.94 & 27 & 12 & 30 & [16] \\
\hline $\mathrm{Ce}_{68} \mathrm{Cu}_{20} \mathrm{Co}_{2} \mathrm{Al}_{10}$ & 0.060 & 16.57 & 30 & 12 & 31 & [61] \\
\hline $\mathrm{Ce}_{68} \mathrm{Cu}_{20} \mathrm{Al}_{10} \mathrm{Fe}_{2}$ & 0.060 & 16.59 & 32 & 12 & 33 & [61] \\
\hline $\mathrm{Ce}_{68} \mathrm{Cu}_{20} \mathrm{Al}_{10} \mathrm{Nb}_{2}$ & 0.060 & 16.70 & 30 & 12 & 31 & [61] \\
\hline $\mathrm{Sc}_{36} \mathrm{Al}_{24} \mathrm{CO}_{20} \mathrm{Y}_{20}$ & 0.081 & 12.39 & 78 & 32 & 85 & {$[3,53]$} \\
\hline $\mathrm{Er}_{50} \mathrm{Al}_{24} \mathrm{CO}_{20} \mathrm{Y}_{6}$ & 0.073 & 13.69 & 65 & 27 & 71 & {$[3,53]$} \\
\hline $\mathrm{Sm}_{40} \mathrm{Y}_{15} \mathrm{Al}_{25} \mathrm{Co}_{20}$ & 0.068 & 14.66 & 55 & 22 & 57 & {$[3,53]$} \\
\hline $\mathrm{Ho}_{35} \mathrm{Y}_{21} \mathrm{Al}_{24} \mathrm{Co}_{20}$ & 0.074 & 13.48 & 64 & 26 & 69 & {$[3,53]$} \\
\hline $\mathrm{Dy}_{46} \mathrm{Al}_{24} \mathrm{Co}_{18} \mathrm{Y}_{10} \mathrm{Fe}_{2}$ & 0.071 & 14.12 & 59 & 24 & 64 & {$[3,53]$} \\
\hline $\mathrm{Tb}_{36} \mathrm{Y}_{20} \mathrm{Al}_{24} \mathrm{Co}_{20}$ & 0.071 & 14.07 & 61 & 24 & 64 & {$[3,53]$} \\
\hline $\mathrm{Gd}_{36} \mathrm{Al}_{24} \mathrm{Co}_{20} \mathrm{Y}_{20}$ & 0.069 & 14.47 & 57 & 24 & 62 & {$[3,53]$} \\
\hline
\end{tabular}


Table 1. (continued)

\begin{tabular}{lcccccc}
\hline \hline Chemical composition & $\begin{array}{c}\text { Molar } \\
\text { density } \\
\text { mol/cm }\end{array}$ & $\begin{array}{c}\text { Molar } \\
\text { volume } \\
\mathrm{cm}^{3} / \mathrm{mol}\end{array}$ & $\begin{array}{c}\text { Bulk } \\
\text { modulus } \\
\mathrm{GPa}\end{array}$ & $\begin{array}{c}\text { Shear } \\
\text { modulus } \\
\mathrm{GPa}\end{array}$ & $\begin{array}{c}\text { Young's } \\
\text { modulus } \\
\mathrm{GPa}\end{array}$ & $\begin{array}{c}\text { Ref. } \\
\mathrm{La}_{66} \mathrm{Al}_{14} \mathrm{Cu}_{10} \mathrm{Ni}_{10}\end{array}$ \\
$\mathrm{Tm}_{39} \mathrm{Y}_{16} \mathrm{Al}_{25} \mathrm{Co}_{20}$ & 0.056 & 17.83 & 35 & 13 & 36 & {$[3,53]$} \\
$\mathrm{Tm}_{55} \mathrm{Y}_{25} \mathrm{Co}_{20}$ & 0.074 & 13.51 & 66 & 30 & 78 & {$[16]$} \\
$\mathrm{Tm}_{45} \mathrm{Y}_{10} \mathrm{Al}_{25} \mathrm{Co}_{20}$ & 0.065 & 15.34 & 62 & 26 & 72 & {$[16]$} \\
$\mathrm{Tm}_{27.5} \mathrm{Y}_{27.5} \mathrm{Al}_{25} \mathrm{Co}_{20}$ & 0.074 & 13.50 & 62 & 27 & 72 & {$[16]$} \\
$\mathrm{Tm}_{40} \mathrm{Zr}_{15} \mathrm{Al}_{25} \mathrm{Co}_{20}$ & 0.072 & 13.81 & 62 & 26 & 68 & {$[16]$} \\
$\mathrm{Lu}_{55} \mathrm{Al}_{25} \mathrm{Co}_{20}$ & 0.077 & 12.97 & 68 & 28 & 74 & {$[16]$} \\
$\mathrm{Lu}_{39} \mathrm{Y}_{16} \mathrm{Al}_{25} \mathrm{Co}_{20}$ & 0.076 & 13.20 & 69 & 31 & 80 & {$[62]$} \\
$\mathrm{Lu}_{45} \mathrm{Y}_{10} \mathrm{Al}_{25} \mathrm{Co}_{20}$ & 0.075 & 13.30 & 71 & 30 & 79 & {$[62]$} \\
$\mathrm{Yb}_{62.5} \mathrm{Zn}_{15} \mathrm{Mg}_{17.5} \mathrm{Cu}_{5}$ & 0.075 & 13.25 & 70 & 31 & 79 & {$[62]$} \\
$\left(\mathrm{Ce}_{0.1} \mathrm{La}_{0.9}\right)_{68} \mathrm{Al}_{10} \mathrm{Cu}_{20} \mathrm{Co}_{2}$ & 0.052 & 19.24 & 20 & 10 & 27 & {$[16]$} \\
$\left(\mathrm{Ce}_{0.8} \mathrm{La}_{0.2}\right)_{68} \mathrm{Al}_{10} \mathrm{Cu}_{20} \mathrm{Co}_{2}$ & 0.057 & 17.63 & 36 & 11 & 30 & {$[16]$} \\
$\mathrm{Sr}_{60} \mathrm{Mg}_{18} \mathrm{Zn}_{22}$ & 0.060 & 16.69 & 32 & 12 & 31 & {$[16]$} \\
$\mathrm{Sr}_{60} \mathrm{Li}_{5} \mathrm{Mg}_{15} \mathrm{Zn}_{20}$ & 0.043 & 23.47 & 15 & 8 & 20 & {$[2]$} \\
$\mathrm{Sr}_{60} \mathrm{Mg}_{20} \mathrm{Zn}_{15} \mathrm{Cu}_{5}$ & 0.043 & 23.29 & 16 & 7 & 18 & {$[2]$} \\
$\mathrm{Sr}_{40} \mathrm{Yb}_{20} \mathrm{Mg}_{20} \mathrm{Zn}_{15} \mathrm{Cu}_{5}$ & 0.043 & 23.17 & 15 & 8 & 20 & {$[2]$} \\
$\mathrm{Sr}_{20} \mathrm{Ca}_{20} \mathrm{Yb}_{20} \mathrm{Mg}_{20} \mathrm{Zn}_{20}$ & 0.045 & 22.15 & 18 & 8 & 21 & {$[2]$} \\
$\mathrm{Zn}_{40} \mathrm{Mg}_{11} \mathrm{Ca}_{31} \mathrm{Yb}_{18}$ & 0.046 & 21.94 & 18 & 9 & 23 & {$[3]$} \\
$\mathrm{Ti}_{40} \mathrm{Zr}_{25} \mathrm{Be}_{35}$ & 0.059 & 16.84 & 20 & 11 & 29 & {$[16]$} \\
\hline \hline
\end{tabular}


[1] Ashby M F 2005 Materials Selection in Mechanical Design. 3 ed (Linacre House, Jordan Hill, Oxford, Elsevier Butterworth-HeinemannSeries)

[2] Zhao K, Li J F, Zhao D Q, Pan M X, Wang W H 2009 Degradable Sr-based bulk metallic glasses Scripta Mater 61 (1091-4)

[3] Wang W H 2012 The elastic properties, elastic models and elastic perspectives of metallic glasses Prog Mater Sci 57 (487-656)

[4] Inoue A, Shen B L, Chang C T $2006 \mathrm{Fe}$ - and Co-based bulk glassy alloys with ultrahigh strength Intermetallics 14 (936-44)

[5] Inoue A, Shen B L, Koshiba H, Kato H, Yavari A R 2004 Ultra-high stength above 5000 MPa and soft magnetic properties of Co-Fe-Ta-B bulk glassy alloys Acta Mater 52 (1631-7)

[6] Schnabel V, Evertz S, Rueß H, Music D, Schneider J M 2015 Stiffness and toughness prediction of Co-Fe-Ta-B metallic glasses, alloyed with $\mathrm{Y}, \mathrm{Zr}, \mathrm{Nb}, \mathrm{Mo}, \mathrm{Hf}, \mathrm{W}, \mathrm{C}, \mathrm{N}$ and $\mathrm{O}$ by ab initio molecular dynamics J Phys: Condens Matter 27 (105502)

[7] Hostert C, Music D, Bednarcik J, Keckes J, Kapaklis V, Hjörvarsson B, et al. 2011 Ab initio molecular dynamics model for density, elastic properties and short range order of Co-Fe-Ta-B metallic glass thin films J Phys: Condens Matter 23 (475401)

[8] Gilman J J 2003 Electronic Basis of the Strength of Materials (Cambridge, United Kingdom, Cambridge University PressSeries)

[9] Li C, Wu P 2001 Correlation of bulk modulus and the constituent element properties of binary intermetallic compounds Chem Mater 13 (4642-8)

[10] Miedema A R 1992 Energy effects and charge transfer in metal physics; modelling in real space Physica $B 182$ (1-17)

[11] Xu B, Wang Q, Tian Y 2013 Bulk modulus of polar covalent crystals Sci Rep 3 (3068)

[12] Wacke S, Gorecki T, Gorecki C, Ksiqzek K 2011 Relations between the cohesive energy, atomic volume, bulk modulus and sound velocity in metals J Phys: Condens Matter 289 (012020)

[13] Pang J J, Tan M J, Liew K M 2013 On valence electron density, energy dissipation and plasticity of bulk metallic glasses J Alloys Compd 577s (S56-S65)

[14] Jiang Q, Chi B Q, Li J C 2003 A valence electron concentration criterion for glass-formation ability of metallic liquids Appl Phys Lett 82 (2984-6)

[15] Kittel C 2005 Introduction to Solid State Physics. 8 ed (New York, John Wiley and SonsSeries)

[16] Zhang S G 2013 Signature of properties in elastic constants of no-metalloid bulk metallic glasses. Intermetallics 35 (1-8)

[17] Bridge B 1989 Improved tests for theoretical model of the bulk modulus of polycomponent inorganic oxide glasses J Mater Sci Let 8 (1060-3)

[18] Rouxel T 2007 Elastic Properties and Short-to Medium-Range Order in Glasses J Am Ceram Soc 90 (3019-39)

[19] Music D, Geyer R W, Schneider J M 2016 Recent progress and new directions in density functional theory based design of hard coatings Surf Coat Tech 286 (178-90)

[20] Ozaki T, Kino H 2005 Efficient projector expansion for the ab initio LCAO method Phys Rev B $72(045121)$

[21] Hohenberg P, Kohn W 1964 Inhomogeneous electron gas Phys Rev 136 (864-71)

[22] Sholl D S 2009 Density functional theory: a practical introduction (Hoboken, New Jersey, John Wiley \& Sons, Inc.Series)

[23] Ozaki T 2003 Variationally optimized atomic orbitals for large-scale electronic structures Phys $\operatorname{Rev} B 67$ (155108)

[24] Kresse G, Fürthmüller J 1996 Efficient iterative schemes for $a b$ initio total-energy calculations using a plane-wave basis set Phys Rev B 54 (11169)

[25] Birch F 1978 Finite strain isotherm and velocities for single-crystal and polycrystalline $\mathrm{NaCl}$ at high pressures and $300^{\circ} \mathrm{K} J$ Geoph Res 83 (1257-68)

[26] Holm B, Ahuja R, Yourdshadyan Y, Johansson B, Lundqvist B I 1999 Elastic and optical properties of $\alpha$ - and $\mathrm{K}-\mathrm{Al}_{2} \mathrm{O}_{3}$ Phys Rev $B 59$ (12777) 
[27] Dronskowski R, Blöchl P E 1993 Crystal Orbital Hamilton Populations (COHP). Energy-resolved visualization of chemical bonding in solids based on density-functional calculations. J Phys Chem 97 (8617-24)

[28] Deringer V L, Tchougreeff A L, Dronskowski R 2011 Crystal Orbital Hamilton Population (COHP) analysis as projected from plane-wave basis sets. J Phys Chem A 115 (5461-6)

[29] Maintz S, Deringer V L, Tchougreeff A L, Dronskowski R 2013 Analytic projection from planewave and PAW wavefunctions and application to chemical-bonding analysis in solids. $J$ Comput Chem 34 (2557-67) [30] Schnabel V, Bednarcik J, Music D, Pazur T, Hostert C, Schneider J M 2015 Temperatureinduced short-range order changes in $\mathrm{CO}_{67} \mathrm{~B}_{33}$ glassy thin films and elastic limit implications Mater Res Let (82-7)

[31] Biloni H, Boettinger W J 1996 Physical Metallurgy. 4 ed North-HollandSeries)

[32] Thompson K, Lawrence D, Larson D J, Olson J D, Kelly T F, Gorman B 2007 In situ site-specific specimen preparation for atom probe tomography Ultramicroscopy 107 (131-9)

[33] Oliver W C, Pharr G M 1992 An improved technique for determining hardness and elastic modulus using load displacement sensing indentation experiments J Mater Res 7 (1564-83)

[34] Hammersley A P, Svensson S O, Hanfland M, Fitch A N, Häusermann D 1995 Tow-dimensional detector software: From real detector to idealised image or two-theta scan. High Press Res 14 (23548)

[35] Soper H E, Young A W, Cave B M, Lee A, Pearson K 1917 On the distribution of the correlation coefficient in small samples. Biometrika 11 (328-413)

[36] Barbee T W, Holmes W H, Keith D L, Pyzyna M K 1977 Synthesjs of amorhpous niobium-nickel by vapor quenching Thin Solid Films 45 (591-9)

[37] Schnabel V, Köhler M, Evertz S, Gamcova J, Bednarcik J, Music D, et al. 2016 Revealing the relationships between chemistry, topology and stiffness of ultrastrong Co-based metallic glass thin films: A combinatorial approach Acta Mater 107 (213-9)

[38] Wang J, Li R, Hua N, Zhang T 2011 Co-based ternary bulk metallic glasses with ultrahigh strength and plasticity J Mater Res 26 (2072-9)

[39] Schnabel V, Jaya B N, Köhler M, Music D, Kirchlechner C, Dehm G, et al. 2016 Electronic hybridisation implications for the damage-tolerance of thin film metallic glasses Sci Rep 6 (36556)

[40] Deringer V L, Zhang W, Lumeij M, Maintz S, Matthias Wuttig, Mazzarello R, et al. 2014 Bonding nature of local structural motifs in amorhpous GeTe Angew Chem Int Ed 53 (10817-20)

[41] Cohen M L 1985 Calculation of bulk moduli of diamond and zinc-blende solids Phys Rev B 32 (7988-91)

[42] Rose J H, Ferrante J, Smith J R 1981 Universal binding energy curves for metals and bimetallic interfaces Phys Rev Lett 47 (675-8)

[43] Banerjea A, Smith J R 1988 Origins of the universal binding-energy relation Phys Rev B 37 (6632-45)

[44] Smith J R, Ferrante J, Rose J H 1982 Universal binding-energy relation in chemisorption Phys Rev $B 25$ (1419-22)

[45] Xi X K, Wang R J, Zhao D Q, Pan M X, Wang W H 2004 Glass-forming Mg-Cu-RE (RE = Gd, Pr, $\mathrm{Nd}, \mathrm{Tb}, \mathrm{Y}$, and Dy) alloys with strong oxygen resistance in manufacturability J Non-Cryst Solids 344 (105-9)

[46] Zhang CM, Hui X, Li Z G, Chen G L 2009 Improving the strength and the toughness of Mg-Cu( $Y, \mathrm{Gd}$ ) bulk metallic glass by minor addition of Nb J Alloys Compd 467 (241-5)

[47] Xi X K, Zhao D Q, Pan M X, Wang W H 2004 Highly processable $\mathrm{Mg}_{65} \mathrm{Cu}_{25} \mathrm{~Tb}_{10}$ bulk metallic glass J Non-Cryst Solids 344 (189-92)

[48] Zheng Q, Ma H, Ma E, Xu J $2006 \mathrm{Mg}-\mathrm{Cu}-(\mathrm{Y}, \mathrm{Nd})$ pseudo-ternary bulk metallic glasses: The effects of $\mathrm{Nd}$ on glass-forming ability and plasticity Scripta Mater 55 (541-4)

[49] Li Z G, Hui X, Zhang C M, Chen G L 2008 Formation of Mg-Cu-Zn-Y bulk metallic glasses with compressive strength over gigapascal J Alloys Compd 454 (168-73) 
1 [50] Duan G, Wiest A, Lind M L, Kahl A, Johnson W L 2008 Lightweight Ti-based bulk metallic 2 glasses excluding late transition metals Scripta Mater 58 (465-8)

3 [51] Zhang Y, Ji Y F, Zhao D Q, Zhuang Y X, Wang R J, Pan M X, et al. 2001 Glass forming ability and 4 properties of Zr/Nb-based bulk metallic glasses Scripta Mater 44 (1107-12)

5 [52] Zhang Y, Zhao D Q, Pan M X, Wang W H 2003 Glass forming properties of Zr-based bulk 6 metallic alloys $J$ Non-Cryst Solids 315 (206-10)

7 [53] Wang W H 2005 Elastic moduli and behaviors of metallic glasses J Non-Cryst Solids 351 (14818 5)

9 [54] Johnson W L, Samwer K 2005 A Universal Criterion for Plastic Yielding of Metallic Glasses with $10 \mathrm{a}\left(\mathrm{T} / \mathrm{T}_{\mathrm{g}}\right)^{2 / 3}$ Temperature Dependence Phys Rev Let 95 (195501)

11 [55] Xu D, Duan G, Johnson W L, Garland C 2004 Formation and properties of new Ni-based 12 amorphous alloys with critical casting thickness up to $5 \mathrm{~mm}$ Acta Mater 52 (3493-7)

13 [56] Wang W, Zhou B 2004 The correlation of damping capacity with grain-boundary precipitates 14 in Fe-Cr-based damping alloys annealed at high temperature Mater Sci Eng, A 366 (45-9)

[57] Inoue A, Zhang W, Zhang T, Kurosaka K 2002 Cu-based bulk glassy alloys with high tensile strength of over $2000 \mathrm{MPa} J$ Non-Cryst Solids 304 (200-9)

[58] Jiao W, Xi X K, Zhao D Q, Pan M X, Wang W H 2010 Fabrication of bulk metallic glasses at the region of multiple quasi-peritectic reactions Intermetallics 19 (586-8)

[59] Senkov O N, Scott J M, Miracle D B 2006 Composition range and/glass forming ability of ternary Ca-Mg-Cu bulk metallic glasses J Alloys Compd 424 (394-9)

[60] Li S, Wang R J, Pan M X, Zhao D Q, Wang W H 2008 Formation and properties of $\mathrm{RE}_{55} \mathrm{Al}_{25} \mathrm{Co}_{20}$ ( $R E=$ Y, Ce, La, Pr, Nd, Gd, Tb, Dy, Ho and Er) bulk metallic glasses J Non-Cryst Solids 354 (1080-8)

[61] Zhang B, Zhao D Q, Pan M X, Wang R J, Wang W H 2006 Formation of cerium-based bulk metallic glasses Acta Mater 54 (3025-32)

[62] Yu H B, Yu P, Bai H Y 2008 Lutetium and thulium based rare earth bulk metallic glasses J NonCryst Solids 354 (4539-42) 